\title{
Attitude of Postmenopausal Women Toward the Menopause and Hormone Treatment in Enugu, Southeast Nigeria
}

\author{
Ijeoma V Ezeome ${ }^{1,2^{*}}$, Joseph O Ezugworie ${ }^{1,2}$, Theophilus O Nwankwo ${ }^{1,2}$
}

\begin{abstract}
Objectives: Menopause is a naturally occurring event in which there is a failure of a woman's ovarian function, thus ending her ability to bear children. However, the attitude of women about menopause and its treatment vary in different societies. The present study assessed postmenopausal women's attitude and knowledge about menopause and hormone treatment (HT) in a private specialist clinic in Enugu, Nigeria.

Materials and Methods: This descriptive cross-sectional survey was conducted on 400 consecutively selected women at the gynecologic clinic of a specialist hospital in Enugu through a structured questionnaire. Descriptive statistics were applied to investigate women's attitudes using SPSS software. The level of significance was estimated by the chi-square test and $\mathrm{P}<0.05$ was considered statistically significant.

Results: The mean age of the respondents at menopause was $48.4( \pm 5.2)$ years, and their ages ranged between 38 and 52 years. A total of $300(75 \%)$ women had at least primary education. In addition, the hot flush was the most common symptom. Further, 236 (59\%) of the respondents obtained their information based on experiences and older women while 64 (16\%) of them received such information from books and the internet. Totally, 148 (37\%) of women sought treatment in the hospital and 196 (49\%) of them had heard of HT mostly from their physician. Even though they were aware that HT relieves hot flushes, they were afraid of the perceived side effects like cancer and heart disease. However, $10.3 \%$ remained as the current users. Given adequate information, $37 \%$ of the respondents would like to use HT.

Conclusions: In general, an increased number of postmenopausal women in Enugu, Nigeria seek relief in the hospital and are becoming aware of HT.

Keywords: Attitude, Menopause, Hormone treatment, Enugu, Nigeria
\end{abstract}

\section{Introduction}

Menopause is found to occur when the menstrual period stops for 12 consecutive months or more in the absence of pregnancy, lactation, or any disease condition due to the decline of estrogen (1). The majority of women assume this period distressful due to the associated symptoms resulting from the absence or fluctuations of the ovarian hormones. These symptoms include hot flushes and night sweats, sexual dysfunction, urinary incontinence, joint pains, and memory loss (2). Regional variation in symptomatology is documented as well (3). According to previous studies, bone and joint pains were most commonly reported in Turkey and rural Nigeria (4) while hot flush in the United Arab Emirates and urban areas of Nigeria $(5,6)$ and irregular menstruation among Saudi women were other reported symptoms of menopause. In general, more symptoms are reported by women with more negative attitudes (7). Postmenopausal Nigerian women were thought not to experience severe menopausal symptoms due to sociocultural factors which encourage a positive attitude about menopause. However, studies in different localities demonstrate that most menopausal symptoms are quite frequent among women (8). Hormone treatment (HT) is confirmed to be most effective in relieving postmenopausal symptoms (9) and preventing long-term complications such as osteoporosis (10). Although some studies report the beneficial effects of HT for coronary heart disease (11), dementia (12), diabetes, and lipid parameters (13), especially when started in the early post-menopause, other studies provide none or negative reports in this regard (14). For example, some studies found its association with an increased risk of stroke, breast malignancy, and thrombotic disease $(14,15)$. Lack of knowledge is found to be greatest among less educated women (16). The findings of some studies conducted in the United States and other developed nations show that women of higher socioeconomic and educational status are more likely to use HT than those of lower social status (10-12). The HT usage is low mainly because the majority remain poorly informed about its

Received 1 March 2018, Accepted 9 September 2018, Available online 9 October 2018

${ }^{1}$ Department of Obstetrics and Gynecology, College of Medicine, University of Nigeria, Enugu Campus, Nigeria. ${ }^{2}$ Department of Obstetrics and Gynecology, University of Nigeria Teaching Hospital, Ituku-Ozalla, Enugu.

*Corresponding Author: Ijeoma V Ezeome, Tel: 08058124721, Email: ezeomeij@gmail.com 
usage (17).

Previous studies from different parts of Nigeria including Enugu (4-6) regarding the attitude of postmenopausal Nigerian women about menopause (18) indicate that they rarely sought treatment for menopausal symptoms and had very little knowledge of HT (19). Christianity is the dominant religion in the Southeastern states of Nigeria, including Enugu and there is no organized state-sponsored mass education program on Women's Health. For over a decade, Churches, village meetings, and Christian Women Organization (CWO) annual August meetings continued to include health talks covering different aspects of women's health in their get-togethers. In these areas, attending such meetings is mandatory for all married women and non-attendance is usually followed by strong reprisals. Access to information via social media and the internet also seem to be easier. Apparently, empirical observations from clinic consultations and casual interactions suggest a positive shift in women's knowledge and attitude about menopause and HT. The present study therefore aimed to scientifically assess the impact of these interventions, as well as to determine the other factors affecting the attitude of postmenopausal women regarding the menopause and HT in a private health facility in Enugu, Southeast Nigeria.

\section{Materials and Methods}

This was a descriptive cross-sectional survey and the sample was drawn from postmenopausal women attending the gynaecological clinic of a specialist health facility in Enugu, South-East, Nigeria from December 1, 2016 to January 31, 2017. An average of 40 gynaecological patients are weekly examined in this center. Most patients that present the clinic are under the Health Maintenance Organizations and reside in different parts of Enugu and its environs.

All consecutive consenting women with no surgical menopause were included in the study using a structured questionnaire which was administered by an interviewer. The questionnaire included information on demographic data such as the age at last menses, the knowledge of menopausal symptoms prior to attaining menopause (good knowledge being 3 or more, and poor knowledge being 0 to 2 symptoms), menopausal symptoms ever experienced, the type of treatment sought, as well as the knowledge of HT and its uptake.

The minimum sample size was determined using the following formula:

$$
N=Z^{2} p q / D^{2}=Z^{2} p(1-p) / D^{2}
$$

where, $N=$ minimum sample size at a $95 \%$ confidence interval, $Z=$ standard normal deviation usually set at 1.96, $p=$ prevalence, $q=1-\mathrm{p}$, and $\mathrm{D}=$ precision, which is the difference between the true population rate and the sample rate and is set at 0.05 .

Using a HT uptake rate of $11.1 \%$ in a previous study in
UNTH, Enugu, South-East Nigeria (19)

$$
\begin{aligned}
& N=1.96^{2} \times 0.11(1-0.11) / 0.05^{2}=1.96^{2} \times 0.11 \times 0.89 / 0.05^{2} \\
& =150.44 .
\end{aligned}
$$

Totally, 438 women were informed about the study purpose, but 30 of them refused to enroll in this study. Informed oral consent was obtained from each participant and they were assured of confidentiality in the use of their data. Further, 8 forms were incompletely filled and thus were not analyzed. A sample of 400 women was deemed appropriate for analysis.

The obtained data were analyzed by SPSS software, version 17 , using descriptive and inferential statistics at 95\% CI. Statistical significance was determined by the chisquare test and $P$ value $<0.05$ was considered statistically significant.

\section{Results}

The mean (SD) of the respondents at menopause was 48.4 $( \pm 5.2)$ years within the range of 33-58 years. A total of 100 $(25 \%)$ of the women had no formal education. Similarly, all respondents were of Igbo tribe and three hundred and $32(83 \%)$ of them were Christians. The demographic characteristics are provided in Table 1.

Three hundred and twenty-five $(81.3 \%)$ women had good knowledge ( 3 or more symptoms) of menopausal symptoms with hot-flush as the most common major symptom that they have ever experienced. Furthermore, 64 (16\%) women obtained their information about menopause from the Internet/books while 48 (12\%) others received the related data from their physician. Finally, $116(29 \%)$ and 124 (31\%) of the respondents obtained information from personal experience and older women, respectively. None of the respondents agreed that health talks in church/village/CWO meetings was a major source of information. Even though the menopausal symptoms failed to prevent 324 (81\%) women from their normal activities, about 180 (45\%) of them sought medical treatment (Table 2).

Among 196 respondents who had heard of HT, 53.1\% obtained their information from their doctor. Although only $16.3 \%$ of women had ever used HT, $10.2 \%$ of them were still current users. Moreover, $91.9 \%$ of the women

Table 1. Age and Educational Level of the Respondents

\begin{tabular}{lcc}
\hline & Number of Respondents & Percent \\
\hline Age at menopause $(\mathrm{y})$ & 24 & 6 \\
$30-39$ & 200 & 50 \\
$40-49$ & 176 & 44 \\
$50-59$ & & \\
Educational level & 100 & 25 \\
Non-formal & 44 & 11 \\
Primary & 108 & 27 \\
Secondary & 148 & 37 \\
Tertiary & & \\
\hline
\end{tabular}


Table 2. Knowledge and Attitude of the Respondents to Menopause

\begin{tabular}{|c|c|c|}
\hline & $\begin{array}{c}\text { No. of } \\
\text { Respondents }\end{array}$ & Percent \\
\hline \multicolumn{3}{|c|}{ Knowledge of menopausal symptoms } \\
\hline Absent period & 380 & 95 \\
\hline Hot flush & 352 & 88 \\
\hline Headache & 324 & 81 \\
\hline Painful intercourse & 312 & 78 \\
\hline Irritation & 312 & 78 \\
\hline \multicolumn{3}{|c|}{ Major ever experienced symptoms } \\
\hline Hot flush & 324 & 81 \\
\hline Irritable & 36 & 9 \\
\hline Painful intercourse & 24 & 6 \\
\hline Joint pains & 16 & 4 \\
\hline \multicolumn{3}{|c|}{ Major source of information on menopause } \\
\hline Older women & 124 & 31 \\
\hline Experience & 116 & 29 \\
\hline Internet/books & 64 & 16 \\
\hline Doctor & 48 & 12 \\
\hline Media & 48 & 12 \\
\hline \multicolumn{3}{|c|}{ Main treatment of menopausal symptoms } \\
\hline No treatment & 204 & 51 \\
\hline Hospital & 148 & 37 \\
\hline Self-medication from chemist & 32 & 8 \\
\hline Herbal medication & 16 & 4 \\
\hline \multicolumn{3}{|l|}{ Prevention from normal activities } \\
\hline Yes & 76 & 19 \\
\hline No & 324 & 81 \\
\hline \multicolumn{3}{|l|}{ Major fear of menopause } \\
\hline Loss of sexual attraction & 268 & 67 \\
\hline Bone fractures & 52 & 13 \\
\hline Aging & 48 & 12 \\
\hline Memory loss & 32 & 8 \\
\hline
\end{tabular}

knew that the relief of hot-flush is a major advantage of HT. Additionally, about $49 \%$ and $44.9 \%$ of the respondents knew that cancer and stroke were the side effects of HT, respectively (Table 3 ).

Totally, 37\% of all the sampled women indicated that they were interested in using HT if well-informed.

There was a significant association between hospital treatment of menopausal symptoms, knowledge, and the uptake of HT with increasing the levels of education (Table 4).

In addition, an increasing number of postmenopausal women obtained information about HT from their doctor and continued using as compared to participants of a previous study conducted in the same locality (Table 5).

\section{Discussion}

Globally, the age of menopause is between 45 and 55 years (1). Based on the findings of this study, the mean
Table 3. Knowledge and Uptake of HT

\begin{tabular}{|c|c|c|}
\hline & $\begin{array}{c}\text { No. of } \\
\text { Respondents }\end{array}$ & Percent \\
\hline \multicolumn{3}{|l|}{ Ever heard of HT } \\
\hline Yes & 196 & 49 \\
\hline No & 204 & 51 \\
\hline Total & 400 & 100 \\
\hline \multicolumn{3}{|c|}{ Source of information on HT 196} \\
\hline Doctor & 104 & 53.1 \\
\hline Friends & 40 & 20.4 \\
\hline Internet & 28 & 14.3 \\
\hline Media & 24 & 12.2 \\
\hline \multicolumn{3}{|l|}{ Ever used HT } \\
\hline Yes & 32 & 16.3 \\
\hline Never used & 164 & 83.7 \\
\hline \multicolumn{3}{|l|}{ Current user of HT } \\
\hline Yes & 20 & 10.2 \\
\hline No & 12 & 6.1 \\
\hline \multicolumn{3}{|c|}{ Known side effects of HT } \\
\hline Cancer & 96 & 49.0 \\
\hline Stroke & 88 & 44.90 \\
\hline Weight gain & 8 & 4.10 \\
\hline Severe headache & 4 & 2.0 \\
\hline \multicolumn{3}{|c|}{ Known advantage of HT } \\
\hline Relieves hot flush & 180 & 91.9 \\
\hline Improve sex & 12 & 6.1 \\
\hline Protect bone & 4 & 2.0 \\
\hline
\end{tabular}

(SD) age at menopause of our respondents was 48.4 $( \pm 5.2)$ years, which is in line with that of other Nigerian studies (4-6,17). Further, the majority of women had good knowledge of menopausal symptoms considering hotflush as the most prevalent experienced symptom. This is in agreement with the findings of other studies in Enugu (18) and other regions in Nigeria $(5,6)$, and the world (3). However, it differs from the finding in rural South-eastern Nigeria (4) where the bone and joint pains were found as the most prevalent symptom, which was probably because most of the women were farmers.

Likewise, most of the women received their information from older women, which corroborates with the finding of the study by Odiari et al (1). The organized health talks in churches/village/CWO meetings appeared to have little if any impact on the source of information about menopause and HT. The lack of privacy and confidentiality during the talks may be an important mitigating factor since these talks were given in a classroom setting and the older women were more likely to speak to the other women personally. The internet and social media also accounted for a very limited source of information. This is probably due to the issue that most women in the postmenopausal age are not 
Table 4. Cross-tabulation of Hospital Treatment of Menopausal Symptoms, Knowledge, and the Uptake of HT and Educational Level

\begin{tabular}{|c|c|c|c|c|c|c|c|}
\hline Variable & $\begin{array}{l}\text { Response } \\
\text { (Yes or No) }\end{array}$ & $\begin{array}{l}\text { Non-formal } \\
\text { Education }\end{array}$ & $\begin{array}{l}\text { Primary } \\
\text { Education }\end{array}$ & $\begin{array}{l}\text { Secondary } \\
\text { Education }\end{array}$ & $\begin{array}{l}\text { Tertiary } \\
\text { Education }\end{array}$ & Total & $\begin{array}{c}\text { Chi-Square/Fisher's Exact } \\
\text { Test }\end{array}$ \\
\hline \multirow{3}{*}{$\begin{array}{l}\text { Hospital treatment } \\
\text { of menopause }\end{array}$} & Yes & $24(16.2 \%)$ & $12(8.1 \%)$ & $28(18.9 \%)$ & $84(56.8)$ & $148(100 \%)$ & \multirow{3}{*}{$\begin{array}{c}\text { Pearson Chi-square value } \\
47.568, \mathrm{df}=3, P=0.000\end{array}$} \\
\hline & No & $76(37.3 \%)$ & $28(13.7 \%)$ & $56(21.5 \%)$ & $44(21.6 \%)$ & 204 (100\%) & \\
\hline & Total & $100(28.4 \%)$ & 40 (11.4\%) & $84(23.9 \%)$ & $128(36.4 \%)$ & 352 (100\%) & \\
\hline \multirow{3}{*}{ Knowledge of HT } & Yes & $16(8.2 \%)$ & $0(0 \%)$ & $68(34.7 \%)$ & 112 (57.1\%) & $196(100 \%)$ & \multirow{3}{*}{$\begin{array}{c}\text { Pearson Chi-square value } \\
136.421, \mathrm{df}=3, P=0.000\end{array}$} \\
\hline & No & $84(41.2 \%)$ & 44 (21.6\%) & 40 (19.5\%) & 36 (17.6\%) & $204(100 \%)$ & \\
\hline & Total & $100(25 \%)$ & 44 (11\%) & $108(27 \%)$ & $148(37 \%)$ & 400 (100\%) & \\
\hline \multirow{3}{*}{ HT Uptake } & Yes & $0(0 \%)$ & & $4(12.5 \%)$ & $28(87.5 \%)$ & $32(100 \%)$ & \multirow{3}{*}{$\begin{array}{l}\text { Fisher's Exact test 14.905, } \\
\qquad P=0.000\end{array}$} \\
\hline & No & $16(9.8 \%)$ & & 64 (39\%) & 84 (51.2\%) & $164(100 \%)$ & \\
\hline & Total & $16(8.2 \%)$ & & $68(34.7 \%)$ & 112 (57.1\%) & $196(100 \%)$ & \\
\hline
\end{tabular}

HT, hormone treatment.

Table 5. Comparative Results of Previous Study in UNTH and Present Study

\begin{tabular}{lcc}
\hline Variable & Previous Studies (18,19) & Present Study \\
\hline Medical treatment of menopause & $144 / 432(33.33 \%)$ & $180 / 400(45.00 \%)$ \\
Knowledge of HT & $168 / 432(38.88 \%)$ & $196 / 400(49.00 \%)$ \\
Information on HT from Doctor & $12 / 168(7.14 \%)$ & $104 / 196(53.06 \%)$ \\
Ever user rate of HT & $48 / 168(28.57 \%)$ & $32 / 196(16.33 \%)$ \\
Current user rate & 0 & $20 / 168(10.20 \%)$ \\
\hline
\end{tabular}

HT, Hormone treatment; UNTH, University of Nigeria Teaching Hospital.

adept in using the internet for medical literature.

The fact that the symptoms did not prevent most of the women from continuing their normal activities probably indicates that most of their symptoms were of mild to moderate severity. Interestingly, about $45 \%$ of the women in our study sought medical treatment to ease their discomfort (37\% in hospital). This differs from the result of a previous study (18) that was also conducted in Enugu Urban and involved 432 respondents with similar sociodemographic characteristics as those of our study group, where $33.3 \%$ sought medical treatment. Our finding may be due to an increased awareness of Nigerian women regarding the available treatment. Clinicians should take advantage of these presentations in the hospital to take an in-depth history and ascertain other symptoms like dyspareunia and the loss of libido which the women may refuse to discuss due to sociocultural reasons. Although menopause was welcomed due to the inconvenience of monthly bleeds, the loss of sexual attraction was considered as the greatest fear of women in this respect. This was similarly reported in other studies $(20,21)$ about menopause, resulting in the removal of taboos and restrictions associated with menstruation (22).

HT is found to be the most effective treatment of climacteric symptoms (23). However, previous research reported the lack of information about HT as the most important reason for its poor or lack of use (24). One-half of the respondents in this study had heard of HT. This result varies from a previous study in Enugu (19), an urban area located in South-East Nigeria, which involved 432 respondents $95 \%$ of whom had at least primary education. In addition, only $38 \%$ of them had ever heard of HT while none of them were as a current user of HT. In Western societies, women have good knowledge of HT but might not use it because they have not discussed it with, or not been recommended by their doctor (25). The source of information on HT in our study was mostly from the doctor. This is supported by many studies $(26,27)$ unlike the previous study in Enugu (19) where the information was mostly from the reading materials and families and was at the risk of being partly incorrect. As regards the number of respondents with knowledge of HT (168) in the previous study, only $7 \%$ obtained their information from the doctor compared to $51 \%$ in the present study. Surprisingly, they obtained an ever-user rate of $28.6 \%$, but no current user despite experiencing menopausal symptoms. The lack of having correct information by their participants or the lack of recommendation by the doctor may account for their findings. The participants of the present study achieved $16.3 \%$ ever-user and $10.3 \%$ current-user rates.

The lack of awareness about the long-term implications of menopause may result in low HT usage rate (28). Most of our respondents were mainly aware of its shortterm benefit of the relief of vasomotor symptoms. This indicates the important role of the doctor in educating women about the short- and long-term consequences of menopause and HT. It was found that more women tend to use HT on the recommendation by their doctor (29) and the most common reason for the continued use of 
HT was the doctor's recommendation (30,31). Practices prescribed by the physician also seem to play a great role in the rate of use (24). Most Nigerian gynecologists continue to use reassurance, anxiolytics, and analgesics for the treatment of menopausal symptoms without offering HT (8). The low HT uptake among our respondents could also be due to the fact that Nigerian women have a low uptake of contraception (32) as the previous users of oral contraception are more willing to use $\operatorname{HT}(32,33)$.

A good number of our respondents were aware of the side effects of HT and refused to use them due to fear. This may be as a result of half-knowledge obtained from books and the internet in this age of information technology. Cancer and stroke were the prevalent side effects they were afraid of. However, it is encouraging that $10.3 \%$ were still current users, starting 2-3 years prior to the study. None of them reported any major side effect, but the most common known side effects were breast tenderness and fluid retention as reported in the United Arab Emirates (3). Caution is called for in the use of HT due to cardiovascular and oncogenic effects from longterm usage (34).

Education has a positive association with knowledge and the use of HT (25) as confirmed in many studies $(35,36)$, including our findings.

The study limitation lies in the women drawn from a single health facility. Large-scale studies on Nigerian women need to be conducted to further confirm our findings.

In conclusion, an increasing number of postmenopausal women in Enugu seek relief of menopause symptoms in the hospital and also have an increased awareness of HT from their physicians. Clinicians should take advantage of this to educate these women on both short- and longterm implications of menopause while offering evidencebased treatment. As a developing country, organized state-sponsored mass education programs targeting preand postmenopausal women go a long way as the source of information on menopause and access to treatment. The findings of this study revealed obvious changes in attitudes and knowledge about HT between 2011 and 2016 compared to previous studies in the same locality, and therefore, may serve as a basis for future comparisons.

\section{Conflict of Interests}

Authors declare that they have no conflict of interests.

\section{Ethical Issues}

The Research Ethics Committee of the University of Nigeria Teaching Hospital (UNTH) Enugu gave approval for conducting this research because the health facility is yet to have a State-recognized Institutional Review Board.

\section{References}

1. Odiari EA, Chambers AN. Perceptions, attitudes, and selfmanagement of natural menopausal symptoms in ghanaian women. Health Care Women Int. 2012;33(6):560-574. doi:1 $0.1080 / 07399332.2012 .655393$

2. Jack-Ide IO, Emelifeonwu EA, Adika AV. Psychological effects and experiences of menopausal women in a rural community in Niger Delta region of Nigeria. Int J Nurs Midwifery. 2014;6(6):74-79. doi:10.5897/IJNM2014.0134

3. Ibrahim OM, Hussein RM. Knowledge, attitude, and prevalence of use of hormone replacement therapy among women in United ARAB Emirates. Asian J Pharm Clin Res. 2016;9(3):154-158.

4. Anolue FC, Dike E, Adogu P, Ebirim C. Women's experience of menopause in rural communities in Orlu, Eastern Nigeria. Int J Gynaecol Obstet. 2012;118(1):31-33. doi:10.1016/j.ijgo.2012.02.014

5. Olaolorun FM, Lawoyin TO. Experience of menopausal symptoms by women in an urban community in Ibadan, Nigeria. Menopause. 2009;16(4):822-830. doi:10.1097/ gme.0b013e318198d6e7

6. Ande AB, Omu OP, Ande OO, Olagbuji NB. Features and perceptions of menopausal women in Benin City, Nigeria. Ann Afr Med. 2011;10(4):300-304. doi:10.4103/15963519.87048

7. Bahri N, Latifnejad Roudsari R, Tohidinik HR, Sadeghi R. Attitudes towards menopause among Iranian women: A systematic review and meta-analysis. Iran Red Crescent Med J. 2016;18(10):e31012. doi:10.5812/ircmj.31012

8. Nkwo PO. Suboptimal management of severe menopausal symptoms by Nigerian Gynaecologists: a call for mandatory continuing medical education for physicians. BMC Womens Health. 2009;9:30. doi:10.1186/1472-6874-9-30

9. de Villiers TJ, Pines A, Panay N, et al. Updated 2013 International Menopause Society recommendations on menopausal hormone therapy and preventive strategies for midlife health. Climacteric. 2013;16(3):316-337. doi:10.310 9/13697137.2013.795683

10. Curry SJ, Krist AH, Owens DK, et al. Screening for osteoporosis to prevent fractures: US Preventive Services Task Force recommendation statement. JAMA. 2018;319(24):2521-2531. doi:10.1001/jama.2018.7498

11. Schierbeck LL, Rejnmark L, Tofteng CL, et al. Effect of hormone replacement therapy on cardiovascular events in recently postmenopausal women: randomised trial. BMJ. 2012;345:e6409. doi:10.1136/bmj.e6409

12. Oppermann K, Fuchs SC, Donato G, Bastos CA, Spritzer PM. Physical, psychological, and menopause-related symptoms and minor psychiatric disorders in a communitybased sample of Brazilian premenopausal, perimenopausal, and postmenopausal women. Menopause. 2012;19(3):355360. doi:10.1097/gme.0b013e31822ba026

13. Crespo CJ, Smit E, Snelling A, Sempos CT, Andersen RE. Hormone replacement therapy and its relationship to lipid and glucose metabolism in diabetic and nondiabetic postmenopausal women: results from the Third National Health and Nutrition Examination Survey (NHANES III). Diabetes Care. 2002;25(10):1675-1680. doi:10.2337/ diacare.25.10.1675

14. Nelson HD, Walker M, Zakher B, Mitchell J. Menopausal hormone therapy for the primary prevention of chronic conditions: a systematic review to update the U.S. Preventive Services Task Force recommendations. Ann 
Intern Med. 2012;157(2):104-113. doi:10.7326/0003-4819157-2-201207170-00466

15. Moyer VA. Menopausal hormone therapy for the primary prevention of chronic conditions: U.S. Preventive Services Task Force recommendation statement. Ann Intern Med. 2013;158(1):47-54. doi:10.7326/0003-4819-158-1201301010-00553

16. Memon FR, Jonker L, Qazi RA. Knowledge, attitudes and perceptions towards menopause among highly educated Asian women in their midlife. Post Reprod Health. 2014;20(4):138-142. doi:10.1177/2053369114557510

17. Pandey U. Awareness of menopause and HRT among women attending OPD of University teaching hospital. Int J Reprod Contracept Obstet Gynecol. 2014;3(4):1033-1036. doi:10.5455/2320-1770.ijrcog20141231

18. Ikeme A, Okeke TC, Akogu S, Chinwuba N. Knowledge and Perception of Menopause and Climacteric Symptoms among a Population of Women in Enugu, South East, Nigeria. Ann Med Health Sci Res. 2011;1(1):31-36.

19. Okeke TC, Akogu SP, Ekwuazi KE, Ezenyeaku CC, Ikeako LC. A survey of women's knowledge and perception of hormone replacement therapy (hrt) in Enugu, South East Nigeria. Niger J Med. 2013;22(4):332-335.

20. Nusrat N, Nishat Z, Gulfareen H, Aftab M, Asia N. Knowledge, attitude and experience of menopause. J Ayub Med Coll Abbottabad. 2008;20(1):56-59.

21. Agwu UM, Umeora OU, Ejikeme BN. Patterns of menopausal symptoms and adaptive ability in a rural population in South-east Nigeria. J Obstet Gynaecol. 2008;28(2):217-221. doi:10.1080/01443610801915637

22. Avis NE, Crawford S. Cultural differences in symptoms and attitudes toward menopause. Menopause Management Primary Care for Middle Life. http://www.menopausemgmt. com/cultural-differences-in-symptoms-and-attitudestoward-menopuse/. Accessed July 31, 2018.

23. Guidozzi F, Alperstein A, Bagratee JS, et al. South African Menopause Society revised consensus position statement on menopausal hormone therapy, 2014. S Afr Med J. 2014;104(8):537-543. doi:10.7196/samj.8423

24. Sood R, Faubion SS, Kuhle CL, Thielen JM, Shuster LT. Prescribing menopausal hormone therapy: an evidencebased approach. Int J Womens Health. 2014;6:47-57. doi:10.2147/ijwh.s38342

25. Vihtamaki T, Savilahti R, Tuimala R. Why do postmenopausal women discontinue hormone replacement therapy? Maturitas. 1999;33(2):99-105. doi:10.1016/SO3785122(99)00047-X
26. Donati S, Satolli R, Colombo C, et al. Informing women on menopause and hormone therapy: Know The Menopause a multidisciplinary project involving local healthcare system. PLoS One. 2013;8(12):e85121. doi:10.1371/journal. pone. 0085121

27. Tao M, Teng Y, Shao H, Wu P, Mills EJ. Knowledge, perceptions and information about hormone therapy (HT) among menopausal women: a systematic review and meta-synthesis. PLoS One. 2011;6(9):e24661. doi:10.1371/ journal.pone.0024661

28. Pinkerton JV, Santoro N. Compounded bioidentical hormone therapy: identifying use trends and knowledge gaps among US women. Menopause. 2015;22(9):926-936. doi:10.1097/gme.0000000000000420

29. Jin F, Tao M, Teng Y, Shao H, Li C, Mills E. Knowledge and attitude towards menopause and hormone replacement therapy in Chinese women. Gynecol Obstet Invest. 2015;79(1):40-45. doi:10.1159/000365172

30. Lewin KJ, Sinclair HK, Bond CM. Women's knowledge of and attitudes towards hormone replacement therapy. Fam Pract. 2003;20(2):112-119. doi:10.1093/fampra/20.2.112

31. Castelo-Branco C, Ferrer J, Palacios S, Cornago S, Peralta S. Spanish post-menopausal women's viewpoints on hormone therapy. Maturitas. 2007;56(4):420-428. doi:10.1016/j. maturitas.2006.11.006

32. Austin A. Unmet contraceptive need among married Nigerian women: an examination of trends and drivers. Contraception. 2015;91(1):31-38. doi:10.1016/j. contraception.2014.10.002

33. Hammar M, Brynhildsen J, Dabrosin L, et al. Hormone replacement therapy and previous use of oral contraceptives among Swedish women. Maturitas. 1996;25(3):193-199. doi:10.1016/S0378-5122(96)01065-1

34. Panay N, Hamoda H, Arya R, Savvas M. The 2013 British menopause society \& women's health concern recommendations on hormone replacement therapy. Menopause Int. 2013;19(2):59-68. doi:10.1177/1754045313489645

35. Keating NL, Cleary PD, Rossi AS, Zaslavsky AM, Ayanian JZ. Use of hormone replacement therapy by postmenopausal women in the United States. Ann Intern Med. 1999;130(7):545-553. doi:10.7326/0003-4819-130-7199904060-00002

36. Mustafa GN, Sabir JM. Perception and experience regarding menopause among menopaused women attending teaching hospitals in Erbil City. Glob J Health Sci. 2012;4(3):170178. doi:10.5539/gjhs.v4n3p170

(c) 2019 The Author (s); This is an open-access article distributed under the terms of the Creative Commons Attribution License (http://creativecommons.org/licenses/by/4.0), which permits unrestricted use, distribution, and reproduction in any medium, provided the original work is properly cited. 